\title{
Numerical Investigation on the Stress Evolution of Welding Process in Aluminium Alloy 2219
}

\author{
Lin NIE*, Yunxin WU**, Hai GONG*** \\ *School of Mechanical and Electronic Engineering, State Key Laboratory of High-Performance Complex Manufacturing \\ (Central South University), Changsha 410083, China, E-mail: nielin@csu.edu.cn \\ **School of Mechanical and Electronic Engineering, State Key Laboratory of High-Performance Complex Manufacturing \\ (Central South University), Changsha 410083, China, E-mail: wu_yunxin@csu.edu.cn \\ ***State Key Laboratory of High-Performance Complex Manufacturing, Central South University, Changsha 410083, \\ China,E-mail: gh_csu@163.com \\ crossref http://dx.doi.org/10.5755/j01.mech.25.1.21934
}

\section{Introduction}

The aluminum alloy (AA2219) has good high/lowtemperature mechanical properties, good fracture toughness, good stress corrosion resistance and weldability. It is the main structural material of propellant tank for space launch vehicles [1-4]. With a complicated structure, the rocket propellant tank is difficult to be formed at one time and its various sections are connected with tungsten inert gas (TIG) welding technology. Due to the highly concentrated instantaneous heat input, residual stress is inevitably generated during and after welding. Its magnitude and distribution have a vital influence on dimensional accuracy, stress corrosion cracking and safe use of rocket tanks, and can even lead to major safety incidents [5-7]. Therefore, a systematical study of the generation and evolution of stress during the welding of AA2219 and accurate obtainment of the distribution state of post-weld residual stress are of great significance to the safety and reliability of welded structures.

At present, scholars have researched a lot on the welding residual stress of $2 \mathrm{xxx}$ aluminum alloy. Huang et al. [7] used the indentation strain-gauge method to measure the residual stress of AA2219 welded joints. The results show that, the maximum tensile stress is $253 \mathrm{MPa}$ and the maximum compressive stress is $-160 \mathrm{MPa}$. Albertini et al. [8] and Du et al. [9] measured the residual stress of AA2219 welded joints by neutron method, X-ray method and holedrilling method, respectively. These methods were found to accurately characterize residual stresses. Owen et al. [10] measured the TIG welding residual stress of AA2024. It was found that the maximum tensile stress in the heat affected zone, the peak value is $60 \%$ of the yield stress of the base metal, and the tensile stress gradually decreases from the welding line to the outside of the panel. Goldak et al. [11] conducted an in-depth study on the heat transfer process of welding, and established a double ellipsoid heat source model suitable for the analysis of arc welding heat transfer. The prediction results are consistent with the actual temperature field, so the model can better predict the heat transfer process of aluminum alloy TIG welding. On the basis of adopting the heat source model, Presto et al. [12] considered the material nonlinearity and the softening behavior of welded joints, and numerical calculated the residual stress field of AA2024 TIG welding. The calculated results and the measurement results of X-rays are consistent, which further improves the simulation accuracy of the welding stress field. Lima et al. [13] used Sysweld to simulate the welding of aluminum alloy, and the results well predicted the residual stress and deformation of butt welding.

In summary, researches on the TIG welding residual stress of 2xxx aluminum alloy are mostly focused on the distribution, characterization methods and prediction of residual stress, the effect of the process parameters on residual stress and the improvement of the accuracy of the calculation model. While there are few studies on the dynamic process of welding in aluminum alloy, especially the aerospace aluminum alloy AA2219.

In this paper, a dynamic welding 3-D finite element model considering material nonlinearity is developed, and the thermo-mechanical coupling process in the welding of AA2219 was numerically analyzed. The generation and evolution of residual stress during the welding process of aluminum alloy is obtained, which provided a basis for controlling welding stress and formulating welding process. In addition, the post-weld residual stress was measured, and compared with the results from numerical analysis.

\section{Experimental}

The welding test was carried out and the residual stress on the surface of welded joint was measured. The measurement results were used to verify the finite element model.

\subsection{Specimen and welding conditions}

The welding material used in this study is AA2219 with a size of $244 \mathrm{~mm} \times 100 \mathrm{~mm} \times 10 \mathrm{~mm}$, as shown in Fig. 1. The chemical composition and mechanical properties of AA2219 is shown in Table 1. The welding parameters are as follows: welding current, $I=240 \mathrm{~A}$; welding voltage, $U=22 \mathrm{~V}$; and welding speed, $v=2 \mathrm{~mm} / \mathrm{s}$, respectively.

Chemical composition and mechanical properties of AA2219

Table 1

\begin{tabular}{|c|c|c|c|c|c|c|c|c|c|c|}
\hline \multicolumn{8}{|c|}{ Chemical composition } & \multirow{2}{*}{$\begin{array}{c}\text { Tensile strength } \\
R_{m}, \mathrm{MPa}\end{array}$} & \multirow{2}{*}{$\begin{array}{c}\text { Yield strength } \\
R_{p 0.2}, \mathrm{MPa}\end{array}$} & \multirow{2}{*}{$\begin{array}{c}\text { Elongation } \\
A, \%\end{array}$} \\
\hline $\mathrm{Cu}$ & $\mathrm{Mn}$ & $\mathrm{Fe}$ & $\mathrm{Si}$ & $\mathrm{Ti}$ & $\mathrm{Mg}$ & $\mathrm{Zr}$ & $\mathrm{Al}$ & & & \\
\hline $0.58 \sim 0.68$ & $0.2 \sim 0.4$ & 0.3 & 0.2 & $0.02 \sim 0.1$ & 0.02 & $0.1 \sim 0.25$ & Bal. & 454 & 356 & 6 \\
\hline
\end{tabular}




\subsection{Residual stress measurement}

Residual stress is measured by using the hole-drilling method. The hole-drilling method is a standard technique for measuring residual stress, as described in detail in Ref. [14, 15]. The welded joint is polished before measuring to remove the weld reinforcement. The dimensional details of the position used to measure the residual stress are shown in Fig. 1. The details of the hole-drilling technique are shown in Fig. 2.

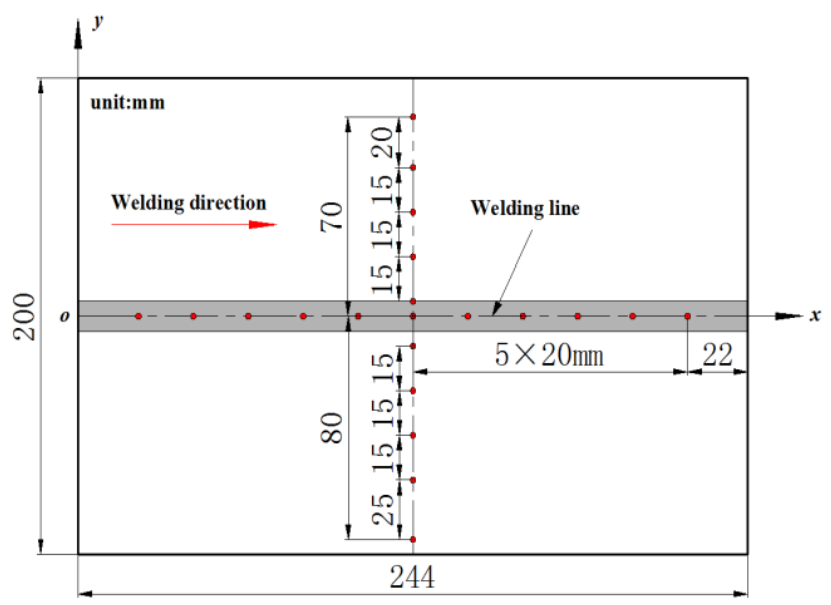

Fig. 1 Dimensional detail of specimen used in the experiment

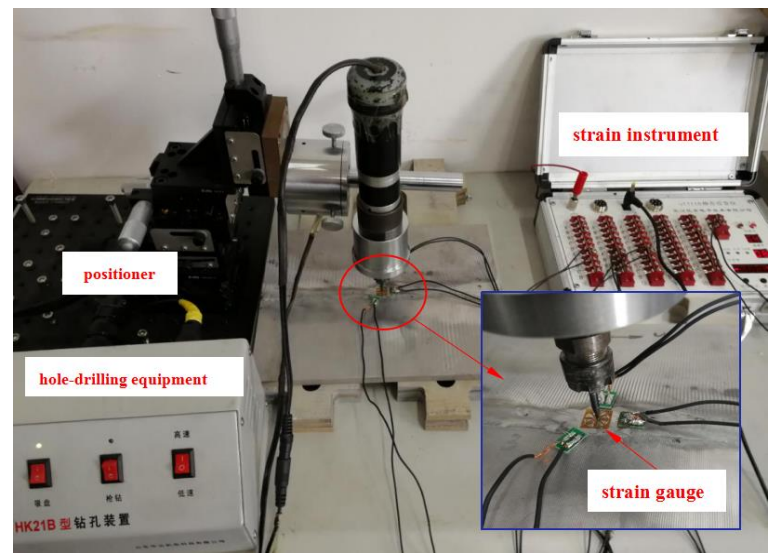

Fig. 2 Details of residual stress measurement through the hole-drilling method

\section{Finite element modelling}

Considering the symmetry of the weldment and the heat source, a finite element model is established by using ABAQUS software, as shown in Fig. 3. The geometric model is meshed by using coupled temperature-displacement element (C3D8RT). It has a fine grid in the welding zone. The smallest element size is $2 \mathrm{~mm} \times 1.5 \mathrm{~mm} \times 1.5 \mathrm{~mm}$, and the number of elements and nodes is 18788 and 22632 , respectively.

\subsection{Thermal analysis}

The governing equation for the calculation of TIG welding heat transfer is [16]:

$\rho c \frac{\partial T}{\partial t}=\frac{\partial}{\partial x}\left(k \frac{\partial T}{\partial x}\right)+\frac{\partial}{\partial y}\left(k \frac{\partial T}{\partial y}\right)+\frac{\partial}{\partial z}\left(k \frac{\partial T}{\partial z}\right)+\bar{q}$, where, $\rho, c$ and $k$ represents the material density, specific heat capacity and thermal conductivity, respectively; $T(x, y$, $z, t$ ) represents the temperature field; $t$ represents the heat transfer time; $\bar{q}$ represents the internal heat source intensity; $x, y, z$ represents the coordinate axis direction.

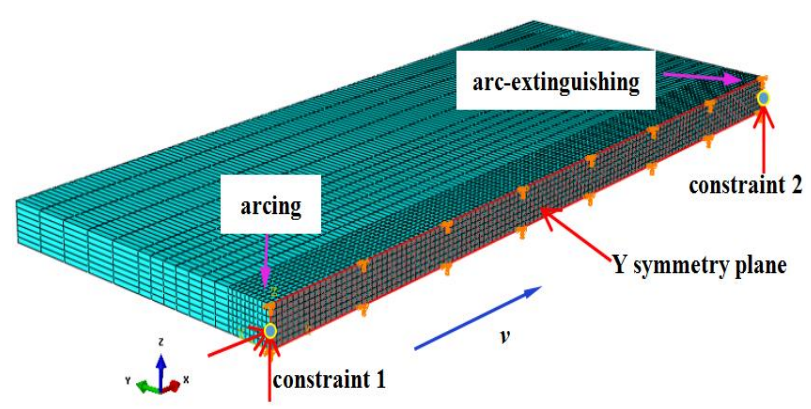

Fig. 3 Finite element model and boundary conditions

The choice of heat source in the welding simulation is related to the welding technology. The double ellipsoid heat source model of Gaussian distribution proposed by Goldak is used for the TIG welding heat source in this paper [11]. The model takes into account the welding speed effect on the heat flux distribution, and the heating area in front of the arc is smaller than the rear of the arc. The mathematical equation of the heat flux distribution in the front and rear half ellipsoids is [17]:

$$
\begin{aligned}
& q_{f}(x, y, z)=\frac{6 \sqrt{3} f_{f} Q}{a_{f} b c \pi \sqrt{\pi}} e^{\left(-\frac{3 x^{2}}{a_{f}^{2}}-\frac{3 y^{2}}{b^{2}}-\frac{3 z^{2}}{c^{2}}\right)}, x \geq 0 ; \\
& q_{r}(x, y, z)=\frac{6 \sqrt{3} f_{r} Q}{a_{r} b c \pi \sqrt{\pi}} e^{\left(-\frac{3 x^{2}}{a_{r}^{2}}-\frac{3 y^{2}}{b^{2}}-\frac{3 z^{2}}{c^{2}}\right)}, x<0 ;
\end{aligned}
$$$$
Q=\eta U I,
$$

where: $Q$ is the effective thermal power for the welding arc; $U$ is the welding voltage; $I$ is the welding current; $\eta$ is the arc thermal efficiency- 0.7 [18]; $a_{f}, a_{r}, b$ and $c$ are the geometric parameters of the double ellipsoid heat source model, representing the front and rear half shaft length, ellipsoid width and depth of the heat source model, respectively. These parameters are related to the characteristics of the welding arc and can be determined by measuring the size of the weld profile [18], as shown in Fig. $4 ; f_{f}, f_{r}$ is the distribution coefficient of the effective thermal power $Q$ in the front and rear half ellipses, which can be calculated as follows $[17,19]$ :

$$
f_{f}=\frac{2}{1+a_{f} / a_{r}}, f_{r}=\frac{2}{1+a_{r} / a_{f}}, f_{f}+f_{r}=2 .
$$

The values of heat source parameters are shown in Table 2.

Table 2

Parameters of heat source shape

\begin{tabular}{|c|c|c|c|}
\hline Parameter & Value & Parameter & Value \\
\hline$a_{f}$ & $0.005 \mathrm{~m}$ & $a_{r}$ & $0.01 \mathrm{~m}$ \\
\hline$b$ & $0.006 \mathrm{~m}$ & $c$ & $0.01 \mathrm{~m}$ \\
\hline$f_{f}$ & 1.33 & $f_{r}$ & 0.67 \\
\hline
\end{tabular}




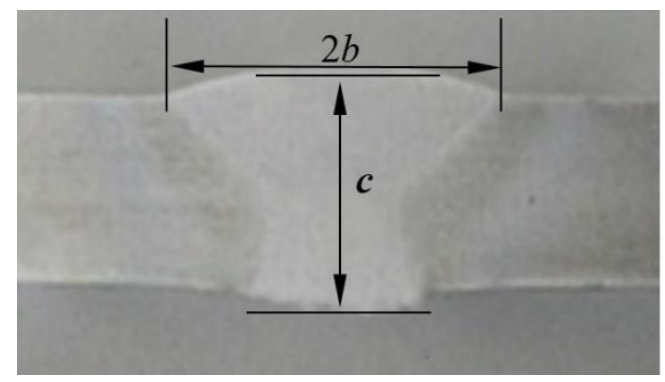

a

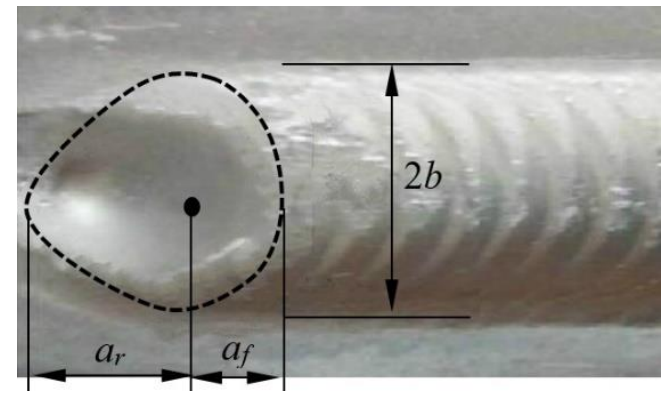

b

Fig. 4 The size of the weld profile: a - the size of the crater, $b$ - the size of the weld section

In the analysis of welding heat transfer, the symmetry plane is the adiabatic boundary. The heat dissipation boundary conditions consider the heat conduction between the weldment and the steel plate, and consider the convective heat transfer and heat radiation between the weldment and the air. Wherein, the heat conduction equivalent treatment between the weldment and the steel plate is convective heat transfer, whose coefficient is $1000 \mathrm{~W} /\left(\mathrm{m}^{2 \circ} \mathrm{C}\right)$ with trial calculation. The convection and heat radiation between the weldment and air are uniformly equivalent to the surface heat exchange effect. The thermal coefficient is calculated according to Eq. (6) $[19,20]$ :

$$
h=h_{a}+\frac{\varepsilon \sigma\left(T^{4}-T_{0}^{4}\right)}{T-T_{0}},
$$

where: $h$ is the equivalent heat transfer coefficient; $h_{a}$ is the convective heat transfer coefficient between the weldment and air, whose value is $20 \mathrm{~W} /\left(\mathrm{m}^{2 \circ} \mathrm{C}\right)$; $\varepsilon$ is the heat radiation coefficient, whose value is $0.75 ; \sigma$ is the Stefan-Boltzman constant, whose value is $5.67 \times 10^{-8} \mathrm{~J} /\left(\mathrm{m}^{2} \mathrm{~s}^{0} \mathrm{C}^{4}\right)$; $T$ is surface temperature; $T_{0}$ is air temperature $\left(25^{\circ} \mathrm{C}\right)$.

\subsection{Mechanical analysis}

The mechanical analysis requires the temperature change in the above heat transfer analysis as the thermal load input to calculate the instantaneous weld thermal stress distribution and the final residual stress distribution. Elasticplastic mechanics analysis involves the following equilibrium equation and constitutive Eqs. [21, 22].

1) Equilibrium equation:

$$
\sigma_{i j, j}+\rho b_{i}=0
$$

where: $\sigma_{i j, j}$ is the stress tensor and $\sigma_{i j}=\sigma_{j i} ; b_{i}$ is the body force.
2) Elasto-plastic constitutive equation:

$$
\begin{aligned}
& {[d \sigma]=\left[D^{e p}\right][d \varepsilon]-\left[C^{t h}\right] d T,} \\
& {\left[D^{e p}\right]=\left[D^{e}\right]+\left[D^{p}\right],}
\end{aligned}
$$

where: $d \sigma$ is the stress increment; $d \varepsilon$ is the strain increment; $d T$ is the temperature increment; $\left[D^{e}\right]$ is the elastic stiffness matrix; $\left[D^{p}\right]$ is the plastic stiffness matrix; $\left[C^{\text {th }}\right]$ is the thermal stiffness matrix.

In mechanical analysis, boundary conditions are only used to prevent rigid motion. Among them, the symmetry plane is fixed in Y-direction, and other conditions are shown in Fig. 3.

\subsection{Material properties}

The specific heat capacity, thermal conductivity, linear expansion coefficient, elastic modulus and yield strength of AA2219 at different temperature are shown in Fig. 5. The data below $400^{\circ} \mathrm{C}$ is obtained by consulting literature [23], and the data above $400^{\circ} \mathrm{C}$ by extrapolation.

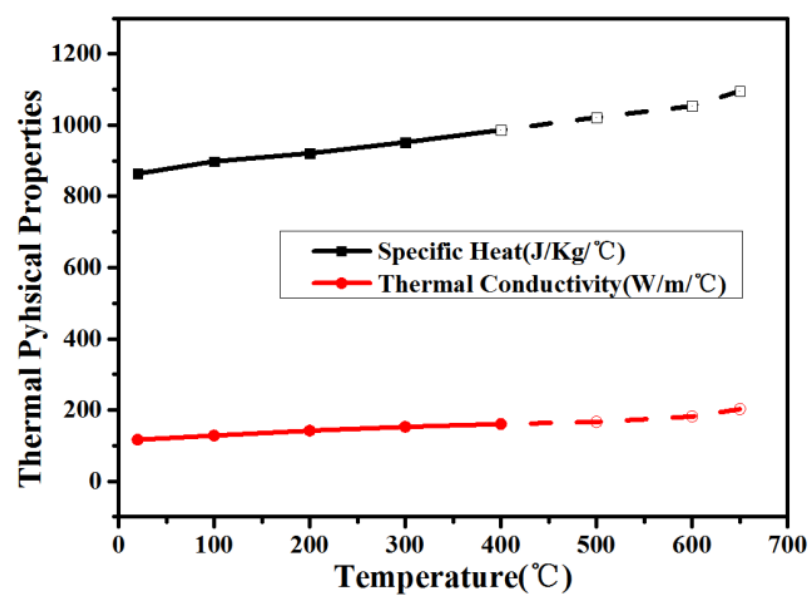

a

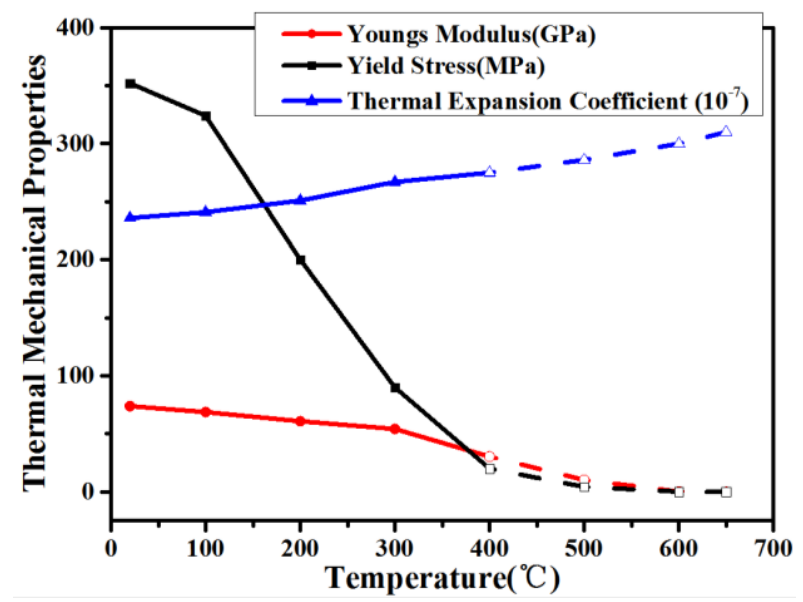

b

Fig. 5 Temperature-dependent material properties of AA2219: a - thermal-physical properties, b - mechanical-physical properties 
There is a certain relationship between the hardness of materials and the yield strength [24]. Therefore, the softening phenomenon of the welded joint can be manifested by setting the material yield strength corresponding to the hardness in different regions. In this paper, the yield strength below $400^{\circ} \mathrm{C}$ after welding that weld zone and heat affected zone is set to be $70 \%$ of the base metal yield strength [12].

Due to the fluid-solid coupling problem in finite element software, when ABAQUS is used to simulate the welding process, the fluid flow and solidification of the material in the welding pool cannot be directly considered. But the fluid flow in the welding pool has significant effects on temperature distribution and the welding pool shape $[18,25]$. If the effect of fluid flow is neglected, the maximum temperature of the welding pool obtained by simulation will be significantly higher than the actual welding temperature. Okagaito [26] studied this and obtained simulation results consistent with the experiment by artificially increasing the thermal conductivity. Therefore, to consider the convective heat diffusion effect generated by the fluid flow in the welding pool, the thermal conductivity of temperature above the melting point in this paper is artificially increased while calculating the temperature field.

\section{Results and discussion}

\subsection{Calculation results of welding stress}

\subsubsection{Stress evolution in the longitudinal section of the weld}

The variation of welding stress $\sigma_{x}=\sigma_{y}$ with time in the longitudinal section of the weld ( $x=0 \sim 244 \mathrm{~mm}$, $y=0 \mathrm{~mm}, z=10 \mathrm{~mm}$ ) is shown in Fig. 6 and Fig. 7. $\sigma_{x}$ is the longitudinal stress along the welding direction and $\sigma_{y}$ is the transverse stress along the vertical welding direction.

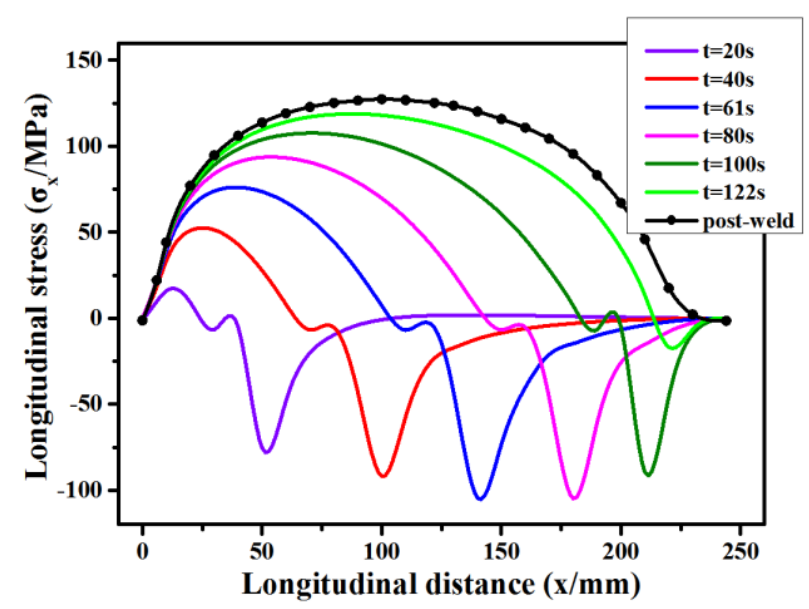

Fig. 6 Dynamic distribution of longitudinal stress in the longitudinal section

Fig. 6 depicts the evolution process of welding stress $\sigma_{x}$ in the longitudinal section of the weld. It can be seen that during the welding ( $t=0 \sim 122 \mathrm{~s}$ ), the heat source area is in an unstressed state and its front end has a large dynamic compressive stress. When $t=61 \mathrm{~s}$, the heat source moves to $x=122 \mathrm{~mm}$, and in front of the heat source about $32 \mathrm{~mm}$, the maximum longitudinal compressive stress appears, which is $-107 \mathrm{MPa}$. After the heat source passes, the dynamic compressive stress at the same position gradually transforms into tensile stress. This is because materials in the welding pool at the heat source are in a molten state with no stress; while the materials at the front end of the heat source begin to thermally expand under the action of high temperature, and compressive stress is generated after being constrained by the compression of surrounding materials; after the heat source passes, materials at the back end begin to cool and shrink, restrained by the tension of surrounding materials, and then the dynamic compressive stress gradually transforms into tensile stress.

After the welding is cooled, the stress tends to be stable. In the arcing and arc-extinguishing areas of the welded joint, their surrounding end faces are free boundaries and the longitudinal stress is in the unstressed state.

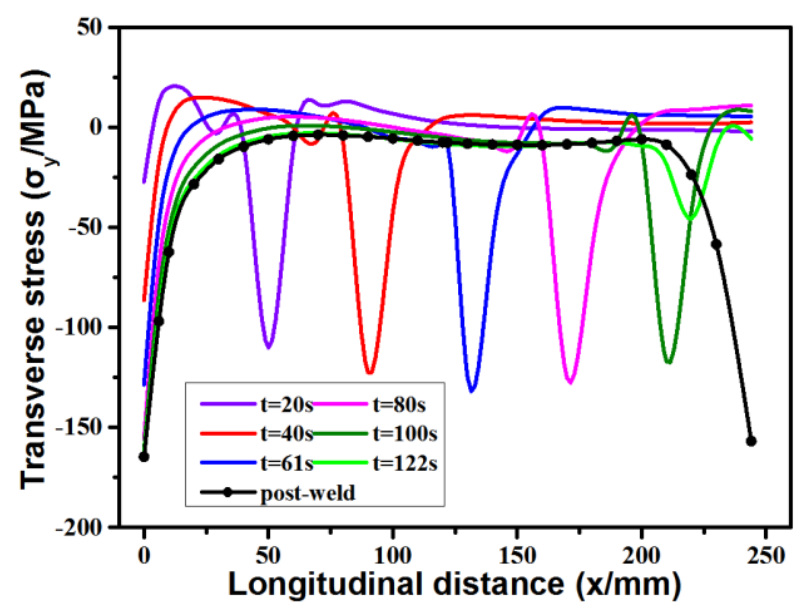

Fig. 7 Dynamic distribution of transverse stress in the longitudinal section

Fig. 7 shows the evolution process of welding stress $\sigma_{y}$ It can be seen that there has a large dynamic transverse compressive stress at the front end of the welding heat source, up to $-126 \mathrm{MPa}$, which is significantly higher than the dynamic longitudinal compressive stress. After the welding stress tends to be stable, the transverse stress is in the state of compressive stress in the arcing and arc-extinguishing areas. The transverse stress changes rapidly in the arcing region, and its maximum compressive stress is greater than the arc-extinguishing zone. The maximum compressive stress at both ends is $-167 \mathrm{MPa}$ and $-155 \mathrm{MPa}$.

\subsubsection{Stress evolution in the cross section of the weld}

Fig. 8 shows the variation of welding stress $\sigma_{x}$ with time in the cross section of the weld ( $x=122 \mathrm{~mm}, y=$ $=0 \sim 100 \mathrm{~mm}, z=10 \mathrm{~mm})$. It can be seen that in the initial stage of welding (0 20 s), the heat source is far from the central cross section, and micro-tensile stress state appears in the near region on both sides of the weld center. As the heat source moves forward $(t=30 \mathrm{~s})$, micro-tensile stress in the vicinity of the weld center turns to compressive stress. As the heat source gradually approaches the central crosssection, the dynamic compressive stress in the vicinity of the weld gradually increases. Meanwhile, the dynamic tensile stress away from the weld also rises slightly. When $t=61 \mathrm{~s}$, the heat source moves to the central cross section $(x=$ $=122 \mathrm{~mm}$ ), the weld center is basically unstressed, but on both sides of the heat source, $y=14 \mathrm{~mm}$ from the welding 
line, there appears the maximum longitudinal compressive stress with $-108 \mathrm{MPa}$. This is because materials in the area where the heat source acts be heated, and the volume expanded to cause a pressing effect on base materials in the vicinity of both sides of the weld.

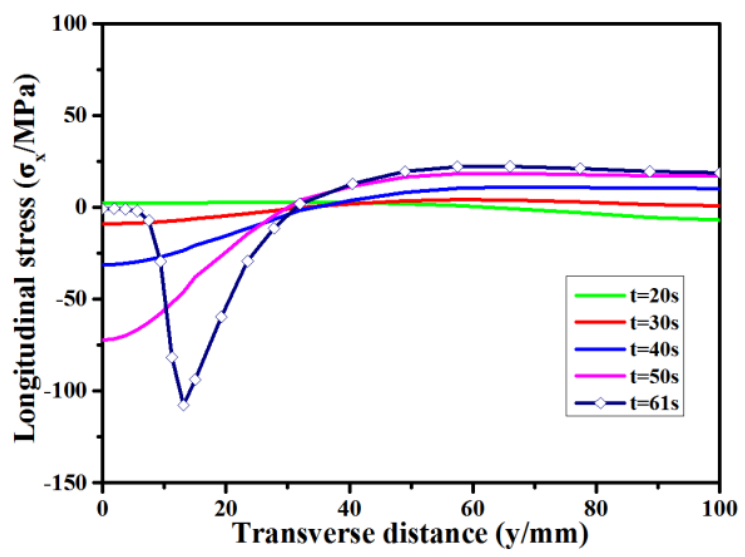

a

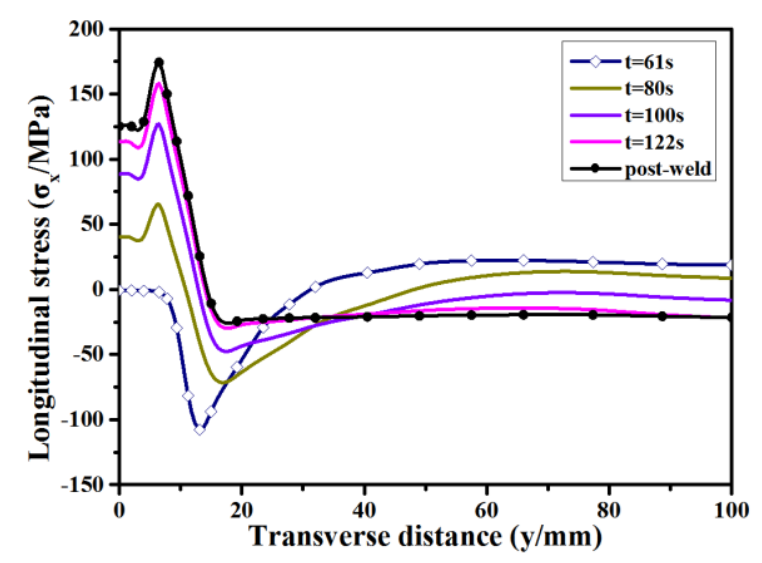

b

Fig. 8 Dynamic distribution of longitudinal stress in the cross section: a - the variation of longitudinal stress with time ( $t \leq 61 \mathrm{~s}), \mathrm{b}$ - the variation of longitudinal stress with time $(t>61 \mathrm{~s})$

After the heat source away from the central cross section $(t>61 \mathrm{~s})$, the vicinity of both sides of the weld gradually changes from the pressure state to the tensile stress state; the stress value gradually increases; the tensile stress region continuously expands to both sides of the weld. This is because the base materials nearing the heat source is thermally expanded when the heat source passes, thereby squeezing the materials in the adjacent area. After the heat source passes, the area cooled and contracted, and the shrinking process is hindered by surrounding materials to generate tensile stress. Therefore, the compressive stress near the weld is gradually reduced and converted into tensile stress. When $t=122 \mathrm{~s}$, the half-width region of the tensile stress at the weld extends to the outside to a range of $14 \mathrm{~mm}$, and the maximum tensile stress at this time is $158 \mathrm{MPa}$.

After the welding is cooled, the stress is basically stable, and the width of the tensile stress region at the weld is basically unchanged. This indicates that the width of the plastic zone has reached the maximum range and has no further expansion after the welding. But during the cooling process, the peak of tensile stress at the weld increases and the compressive stress away from the weld tends to be uniform.
Situated in the heat affected zone, the maximum longitudinal tensile stress in the final is $174 \mathrm{MPa}, 6.5 \mathrm{~mm}$ from the welding line

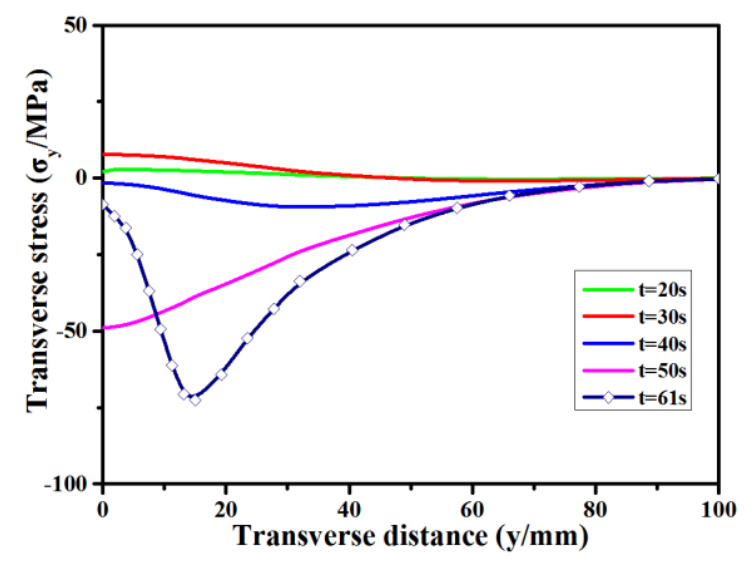

a

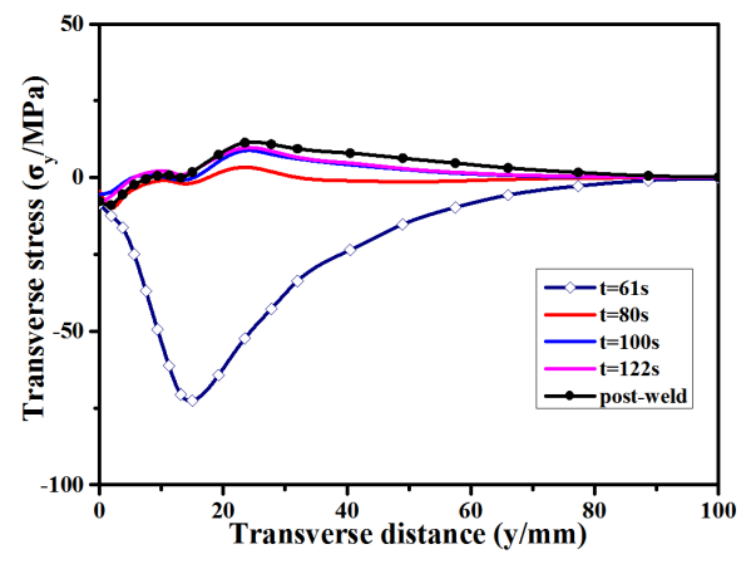

b

Fig. 9 Dynamic distribution of transverse stress in the cross section: a - the variation of transverse stress with time $(t \leq 61 \mathrm{~s}), \mathrm{b}-$ the variation of transverse stress with time $(t>61 \mathrm{~s})$

Fig. 9 shows the variation of welding stress $\sigma_{y}$ over time in the cross section of the weld. At the beginning of welding, the heat source is far from the central cross section, and the weld is in the state of tensile stress. When the heat source is close to the central cross section, dynamic transverse compressive stress appears on both sides of the weld and gradually rises as the heat source moves forward, which is consistent with the analysis results of Fig. 8. When $t=$ $=61 \mathrm{~s}$, the maximum dynamic compressive stress $(-72 \mathrm{MPa})$ appears at $14 \mathrm{~mm}$ from both sides of the heat source. After the heat source leaves the central cross section, the weld begins to cool; the compressive stress on both sides begins to decrease gradually and is redistributed at different parts, and finally tends to be uniformized. After the stabilization, the transverse stress is small.

\subsection{Comparison with experimental measurements}

To verify the accuracy of the calculated residual stress, the distribution of the longitudinal and transverse residual stress was measured by the hole-drilling method after welding. Then the numerical results are compared with the experimental results, as shown in Table 3 and Table 4. 
Table 3

Longitudinal and transverse residual stress across longitudinal section of weld

\begin{tabular}{|c|c|c|c|c|}
\hline \multirow{2}{*}{ Position } & \multicolumn{2}{|c|}{ Longitudinal stress } & \multicolumn{2}{c|}{ transverse stress } \\
\cline { 2 - 5 } & experimental results & numerical results & experimental results & numerical results \\
\hline$x=22 \mathrm{~mm}$ & 18.57 & 77.08 & -126.21 & -28.52 \\
\hline$x=42 \mathrm{~mm}$ & 98.19 & 106.03 & -18.27 & -9.69 \\
\hline$x=62 \mathrm{~mm}$ & 103.32 & 119.09 & -25.11 & -4.32 \\
\hline$x=82 \mathrm{~mm}$ & 117.47 & 125.18 & 17.09 & -4.12 \\
\hline$x=102 \mathrm{~mm}$ & 114.33 & 127.37 & -27.24 & -5.72 \\
\hline$x=122 \mathrm{~mm}$ & 119.41 & 125.16 & -40.57 & -7.74 \\
\hline$x=142 \mathrm{~mm}$ & 112.24 & 120.12 & -16.05 & -8.67 \\
\hline$x=162 \mathrm{~mm}$ & 106.05 & 110.78 & -22.16 & -8.98 \\
\hline$x=182 \mathrm{~mm}$ & 89.29 & 95.54 & 14.52 & -7.86 \\
\hline$x=202 \mathrm{~mm}$ & 70.71 & 66.99 & -13.57 & -6.06 \\
\hline$x=222 \mathrm{~mm}$ & 14.54 & 17.48 & -104.95 & -23.75 \\
\hline
\end{tabular}

Table 4

Longitudinal and transverse residual stress across cross section of weld

\begin{tabular}{|c|c|c|c|c|}
\hline \multirow{2}{*}{ Position } & \multicolumn{2}{|c|}{ Longitudinal stress, MPa } & \multicolumn{2}{c|}{ transverse stress, MPa } \\
\cline { 2 - 5 } & experimental results & numerical results & experimental results & numerical results \\
\hline$y=5 \mathrm{~mm}$ & 164.56 & 174.21 & 3.89 & -2.29 \\
\hline$y=-10 \mathrm{~mm}$ & 63.8 & 71.91 & 13.27 & 0.74 \\
\hline$y=20 \mathrm{~mm}$ & -23.47 & -24.4 & 22.28 & 7.48 \\
\hline$y=-25 \mathrm{~mm}$ & -35.84 & -21.89 & 20.82 & 11.35 \\
\hline$y=35 \mathrm{~mm}$ & -18.26 & -21.68 & 16.64 & 9.37 \\
\hline$y=-40 \mathrm{~mm}$ & -22.74 & -21.03 & 8.42 & 7.96 \\
\hline$y=50 \mathrm{~mm}$ & -21.51 & -20.34 & 6.37 & 6.31 \\
\hline$y=-55 \mathrm{~mm}$ & -26.44 & -19.76 & 2.79 & 4.72 \\
\hline$y=70 \mathrm{~mm}$ & -14.79 & -19.55 & 3.62 & 1.68 \\
\hline$y=-80 \mathrm{~mm}$ & -23.32 & -20.65 & 5.23 & 0.59 \\
\hline
\end{tabular}

It can be seen that the experimental measurement data is basically consistent with the numerical calculation, which indicates that the calculation model is reliable. In addition, the measurement results show that the weld bead is mainly dominated by longitudinal tensile stress, and the maximum longitudinal tensile stress is $165 \mathrm{MPa}$, which is about $47 \%$ of the yield strength of the base metal.

\section{Conclusions}

1. The longitudinal and transverse dynamic compressive stresses are generated in the front end and both sides of the heat source during the welding process.

2. After the heat source passes, the dynamic compressive stress of the weld and its vicinity of both sides gradually transforms into tensile stress, and the stress value gradually increases. Meanwhile, the distribution range of longitudinal tensile stress continuously expands to both sides of the weld, and reaches the maximum width after arcing extinction.

3. The post-weld residual stress in the weld is mainly dominated by longitudinal tensile stress, and the half-width of the tensile stress distribution is $14 \mathrm{~mm}$. The maximum longitudinal tensile stress is $165 \mathrm{MPa}$, which is about $47 \%$ of the yield strength of the base metal, and is located in the heat affected zone.

4. There has a large transverse compressive stress in the arcing and arc-extinguishing areas, and the maximum compressive stress is located at the arcing point. In addition, the transverse stress in the middle of the weld is small.

\section{References}

1. Dursun, T.; Soutis, C. 2014. Recent developments in advanced aircraft aluminium alloys, Materials and Design 56(4): 862-871. https://doi.org/10.1016/j.matdes.2013.12.002.

2. Kaibyshev, R.; Sitdikov, O.; Mazurina, I.; Lesuer, D.R. 2002. Deformation behavior of a 2219 al alloy, Materials Science and Engineering A 334(1): 104113. https://doi.org/10.1016/S0921-5093(01)01777-4.

3. Narayana, G. V.; Sharma, V. M. J.; Diwakar, V.; Kumar, K. S.; Prasad, R. C. 2004. Fracture behaviour of aluminium alloy 2219-T87 welded plates, Science and technology of welding and joining 9(2): 121-130. https://doi.org/10.1179/136217104225017035.

4. Wang, H.; Yi, Y.; Huang, S. 2016. Influence of predeformation and subsequent ageing on the hardening behavior and microstructure of 2219 aluminum alloy forgings, Journal of Alloys and Compounds 685: 941-948. https://doi.org/10.1016/j.jallcom.2016.06.111.

5. Jiang, W. C.; Wang, B. Y.; Gong, J. M.; Tu, S. T. 2011. Finite element analysis of the effect of welding heat input and layer number on residual stress in repair welds for a stainless steel clad plate, Materials and Design 32(5): 2851-2857.

https://doi.org/10.1016/j.matdes.2010.12.037.

6. Ahi, A. M.; Yousefi, J.; Najafabadi, M. A.; Esmaeilzare, A.; Oskouei, A. R. 2017. Residual stress evaluation in friction stir-welded aluminum plates using finite element method and acoustic emission, Journal of Materials Science 52(4): 2103-2116. https://doi 10.1007/s10853-016-0498-Z.

7. Huang, C.; Li, H.; Li, J.; Luo, C.; Ni, Y. 2017. Residual stress measurement on propellant tank of 2219 alu- 
minum alloy and study on its weak spot, Journal of Mechanical Science and Technology 31(5): 2213-2220. https://doi 10.1007/s12206-017-0417-5.

8. Albertini, G.; Bruno, G.; Dunn, B. D.; Fiori, F.; Reimers, W.; Wright, J. S. 1997. Comparative neutron and X-ray residual stress measurements on A1-2219 welded plate. Materials Science and Engineering A 224(96): 157-165. https://doi: 10.1016/S0921-5093(96)10546-3 \}.

9. Du, Y.; Li, H.; Yang, L.; Luo, C. 2018. Accurate measurement of residual stresses of 2219-t87 aluminum alloy friction stir welding joints based on properties of joints, Journal of Mechanical Science and Technology 32(1): 139-147. https://doi 10.1007/s12206-017-1215-9.

10. Owen, R.A.; Preston, R.V.; Withers, P. J.; Shercliff, H. R.; Webster, P. J. 2003. Neutron and synchrotron measurements of residual strain in tig welded aluminium alloy 2024, Materials Science and Engineering A 346(1): 159-167. https://doi.org/10.1016/S0921-5093(02)00547-6.

11. Goldak, J.; Chakravarti, A.; Bibby, M. 1984. A new finite element model for welding heat sources, Metallurgical Transactions B 15(2): 299-305.

12. Preston, R. V.; Shercliff, H. R.; Withers, P. J.; Smith, S. 2004. Physically-based constitutive modelling of residual stress development in welding of aluminium alloy 2024, Acta Materialia 52(17): 4973-4983. https://doi.org/10.1016/j.actamat.2004.06.048.

13. Lima, T. R.; Tavares, S. M. O.; Castro, P. M. S. T. D. 2017. Residual stress field and distortions resulting from welding processes: numerical modelling using sysweld, Ciencia E Tecnologia Dos Materiais 29(1): e56-e61. https://doi 10.1016/j.ctmat.2016.07.015.

14. Standard test method for determining residual stresses by the hole-drilling strain-gage method. ASTM E83708.

15. Rossini, N. S.; Dassisti, M.; Benyounis, K. Y.; Olabi, A. G. 2012. Methods of measuring residual stresses in components, Materials and Design 35(119): 572-588. https://doi.org/10.1016/j.matdes.2011.08.022.

16. Deng, D.; Murakawa, H. 2006. Numerical simulation of temperature field and residual stress in multi-pass welds in stainless steel pipe and comparison with experimental measurements, Computational Materials Science 37(3): 269-277.

https://doi.org/10.1016/j.commatsci.2005.07.007.

17. Hwang, S. Y.; Kim, Y.; Lee, J. H. 2016. Finite element analysis of residual stress distribution in a thick plate joined using two-pole tandem electro-gas welding, Journal of Materials Processing Technology 229(2016): 349360. https://doi.org/10.1016/j.jmatprotec.2015.09.037.

18. Deng, D. 2009. FEM prediction of welding residual stress and distortion in carbon steel considering phase transformation effects, Materials and Design 30(2): 359366. https://doi.org/10.1016/j.matdes.2008.04.052.

19. Long, H.; Gery, D.; Carlier, A.; Maropoulos, P. G. 2009. Prediction of welding distortion in butt joint of thin plates, Materials \& Design 30(10): 4126-4135. https://doi.org/10.1016/j.matdes.2009.05.004.

20. Joshi, S.; Hildebrand, J.; Aloraier, A. S.; Rabczuk, T. 2013. Characterization of material properties and heat source parameters in welding simulation of two overlapping beads on a substrate plate, Computational Materials Science 69(1): 559-565.

https://doi.org/10.1016/j.commatsci.2012.11.029.

21. Teng, T. L.; Chang, P. H.; Tseng, W. C. 2003. Effect of welding sequences on residual stresses, Computers and Structures 81(5): 273-286.

https://doi.org/10.1016/S0045-7949(02)00447-9.

22. Moein, H.; Sattari-Far, I. 2014. Different finite element techniques to predict welding residual stresses in aluminum alloy plates, Journal of Mechanical Science and Technology 28(2): 679-689. https://doi 10.1007/s12206-013-1131-6.

23. Committee, A. I. H.; Davis, J. R. 1990. Properties and selection nonferrous alloys and special-purpose materials, Metals Handbook 2: 62-122.

24. Zhang, P.; Li, S. X.; Zhang, Z. F. 2011. General relationship between strength and hardness, Materials Science and Engineering A 529(1): 62-73. https://doi.org/10.1016/j.msea.2011.08.061.

25. Zhu, X. K.; Chao, Y. J. 2002. Effects of temperaturedependent material properties on welding simulation, Computers and Structures 80(11): 967-976. https://doi.org/10.1016/S0045-7949(02)00040-8.

26. Okagaito, T.; Ohji, T.; Miyasaka, F. 2004. UV radiation thermometry of tig weld pool-development of uv radiation thermometry (report 1), Quarterly Journal of the Japan Welding Society 22(1): 21-26.

\section{Nie, Y. Wu, H. Gong \\ NUMERICAL INVESTIGATION ON THE STRESS EVOLUTION OF WELDING PROCESS IN ALUMINIUM ALLOY 2219}

S u m m a r y

In this paper, a dynamic welding model of tungsten inert gas welding is established to study the evolution of stress during welding and the distribution of residual stress. The residual stress of post-weld is measured by the holedrilling method and compared with the simulation results to verify the validity of the calculation model. The results show that there has a large instantaneous compressive stress existing in the front end and both sides of heat source during the welding process. After the heat source passes, the dynamic compressive stress at the back-end of heat source gradually transforms into tensile stress and the tensile stress region continuously expands to both sides of the weld. The residual stress of post-weld in the weld is mainly dominated by longitudinal tensile stress. The maximum tensile stress of post-weld is $165 \mathrm{MPa}$, which is about $47 \%$ of the yield strength of the base metal, and is located in the heat-affected zone.

Keywords: stress evolution, welding process, finite element analysis, aluminum alloys.

Received October 28, 2018 Accepted January 15, 2019 